Brit. J. vener. Dis. (1958), 34, 223.

\title{
RESULTS OF THE TREATMENT OF GONORRHOEA IN THE BIRMINGHAM CLINIC*
}

\author{
BY \\ GERALD KNIGHT \\ General Hospital, Birmingham
}

Since 1945 there has been considerable regional variation in the problems facing the venereologist. Some figures from an inland industrial area may, therefore, be of general interest. In Birmingham there is a large immigrant population, mainly Carribean, but with a sprinkling of Indians and Pakistanis. The economic situation has been, on the whole, satisfactory, though some patients pay one visit to the clinic and then move on. The number of prostitutes in the area seems to be small and the main source of infection appears to lie in enthusiastic amateurs, largely late teenagers.

Material.-This survey deals with male gonorrhoea cases seen during the years 1955, 1956, and 1957 (Table I).

TABLE I

MALE CASES OF GONORRHOEA

\begin{tabular}{|c|c|c|c|}
\hline Year & 1955 & 1956 & 1957 \\
\hline No. of Cases $\ldots \quad \ldots$ & 444 & 858 & 1,063 \\
\hline
\end{tabular}

The first half of 1958 (i.e. until June 30) produced 544 cases, compared with 483 in the first half of 1957 , so that it is not unreasonable to assume that the rise is not yet halted. The figures relate to infections so that one individual may appear more than once.

These cases have been analysed by race; so few African Negroes have been seen (only twenty in the 3 years) that they have been included with the West Indians (Table II, Fig. 1).

TABLE II

MALE CASES OF GONORRHOEA, BY RACE

\begin{tabular}{l|cccc|c|c|c|c}
\hline Year &.. &.. &.. &.. & 1955 & 1956 & 1957 & Total \\
\hline \multirow{4}{*}{ Race } & White &.. &. &.. & 261 & 307 & 430 & 998 \\
\cline { 2 - 8 } & Indian and Pakistani &.. & 44 & 71 & 110 & 225 \\
\cline { 2 - 8 } & West Indian &. &.. & 139 & 480 & 523 & 1,122 \\
\hline
\end{tabular}

It is clear that, although the West Indians may have been initially responsible for the rise in gonorrhoea, the

* Paper read to M.S.S.V.D. at Addenbrooke's Hospital, Cambridge, on July $5,1958$.

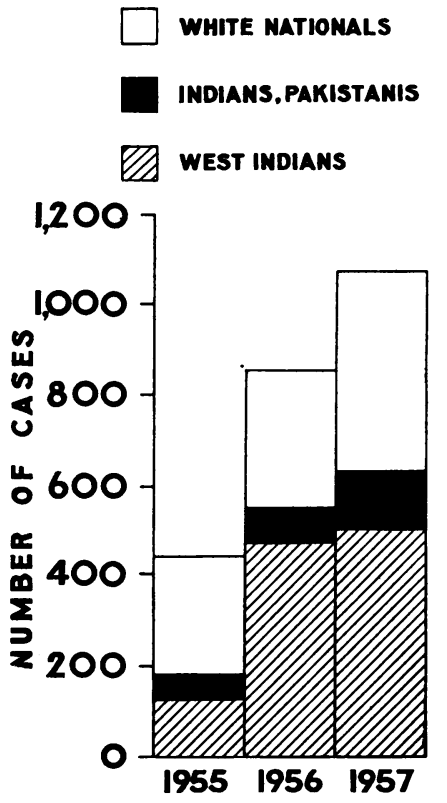

Fig. 1.-Incidence of male gonorrhcea.

increase has occurred in all groups. Laird found in Manchester that Indians and Pakistanis were not an important factor where actual venereal disease was concerned, but in Birmingham they have maintained their 10 per cent. of the gonorrhoea cases ( 110 out of 1,063 in 1957).

Treatment.-One injection of 300,000 units procaine penicillin was given as soon as a diagnosis was established. Each patient was also given a supply of sulphathiazole tablets, $0.5 \mathrm{~g}$. four times daily for a week. In the last quarter of 1957 , the experiment of giving two doses of 300,000 units procaine penicillin on successive days was tried in alternate cases, but as one would expect the results were no better than in those cases in which only one dose was given. Films and cultures after prostatic massage were taken 1, 2, 3, and 4 weeks after treatment, and thereafter at monthly intervals for a total of 6 months. A sound was passed at the end of the first month. 
Defaulters.-The percentage of patients who defaulted after treatment but before any tests had been taken remained fairly constant in the years under review (Table III, Fig. 2).

TABLE III

DEFAULTERS (PERCENTAGE)

\begin{tabular}{lll|l|l|l}
\hline Year & $\ldots$ & $\ldots$ & 1955 & 1956 & 1957 \\
\hline Defaulters & $\ldots$ & $\ldots$ & $16 \cdot 2$ & $15 \cdot 3$ & $16 \cdot 1$ \\
\hline
\end{tabular}

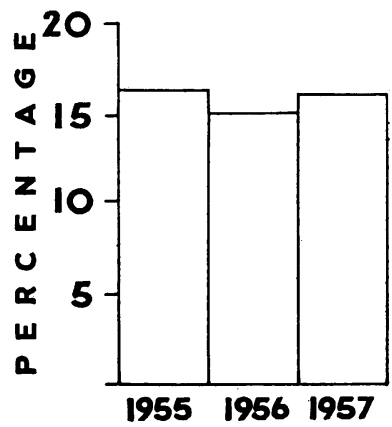

Fig. 2.-Percentage early defaulters.

Results.-All races were represented among the early defaulters and these cases were omitted in assessing the results of the treatment.

Of the remainder, those who did not do well may be classified in four groups:

(1) Failure-where the first test was still positive (Table IV; Fig. 3, opposite).

(2) Reappearance of gonococci after one or more negative tests but within one month of first attendance (Table V; Fig. 4, opposire).

(3) Reappearance of gonococci between 1 and 3 months after first attendance. These are almost certainly re-infections (Table VI; Fig. 5, opposite).

(4) Reappearance of gonococci between 3 and 12 months after first attendance. These are certainly re-infections (Table VII; Fig. 6, opposite).

Certain clinicians claim to be able to distinguish a relapse from a re-infection; there seems, however, to be no possible clinical or bacteriological means of making a scientific distinction, and in the following assessment no attempt has been made to do so.

The failures and recurrences are shown in Tables IV to VII as percentages of the total number of patients who had at least one test after treatment.

The failures show a marked increase in 1957 after a fall in 1956. The increase is seen in all races but especially in the white patients.

The total number of cases recurring in the first month fell slightly in 1957 , the decisive fall in West
TABLE IV

FAILURES (PERCENTAGE)

\begin{tabular}{|c|c|c|c|c|c|c|c|}
\hline Year & .. & . & . & .. & 1955 & 1956 & 1957 \\
\hline \multirow{4}{*}{ Race } & White & . & .. & . & $1 \cdot 4$ & 0.6 & $2 \cdot 7$ \\
\hline & \multicolumn{3}{|c|}{ Indian and Pakistani } & .. & 0.55 & 0.3 & $0 \cdot 3$ \\
\hline & \multicolumn{2}{|c|}{ West Indian } & .. & .. & $1 \cdot 1$ & $1 \cdot 4$ & $4 \cdot 3$ \\
\hline & Total & & .. & .. & 3.05 & $2 \cdot 3$ & $7 \cdot 3$ \\
\hline
\end{tabular}

TABLE V

RECURRENCE IN FIRST MONTH (Percentage)

\begin{tabular}{l|lllll|c|c|c}
\hline Year & $\ldots$ &. &.. &.. &.. & 1955 & 1956 & 1957 \\
\cline { 2 - 7 } Race & White &. &.. &.. & 0.5 & 0.9 & 1.5 \\
\cline { 2 - 7 } & Indian and Pakistani &.. & 0.8 & 0.15 & 0.3 \\
\cline { 2 - 7 } & West Indian &.. &.. & 0.8 & 3.8 & 2.7 \\
\hline & Total &. &. &. & 2.1 & 4.85 & 4.5 \\
\hline
\end{tabular}

TABLE VI

RECURRENCE IN I TO 3 MONTHS (Percentage)

\begin{tabular}{c|ccccc|c|c|c}
\hline Year &. &. &. &. &. & 1955 & 1956 & 1957 \\
\hline \multirow{4}{*}{ Race } & White &.. &.. &.. & 1.1 & 1.2 & 1.5 \\
\cline { 2 - 7 } & Indian and Pakistani &.. & 0.8 & 0.45 & 0.2 \\
\cline { 2 - 7 } & West Indian &.. &.. & 1.1 & 5.4 & 4.3 \\
\hline & Total &. &. &. & 3.0 & 7.05 & 6.0 \\
\hline
\end{tabular}

TABLE VII

RECURRENCE IN 3 TO 12 MONTHS (Percentage)

\begin{tabular}{|c|c|c|c|c|c|c|c|}
\hline Year & . & .. & $\cdots$ & .. & 1955 & 1956 & 1957 \\
\hline \multirow{4}{*}{ Race } & White & . & .. & .. & $2 \cdot 4$ & 0.75 & $2 \cdot 6$ \\
\hline & \multicolumn{3}{|c|}{ Indian and Pakistani } & .. & $1 \cdot 1$ & $2 \cdot 3$ & $1 \cdot 1$ \\
\hline & \multicolumn{2}{|c|}{ West Indian } & .. & . . & $4 \cdot 6$ & $9 \cdot 3$ & $5 \cdot 6$ \\
\hline & Total & & .. & .. & $8 \cdot 1$ & $12 \cdot 35$ & $9 \cdot 3$ \\
\hline
\end{tabular}

Indian cases being partly off-set by a rise in white patients, and, to a lesser extent, in Indians and Pakistanis.

There was a fall in the total number of cases recurring 1 to 3 months after treatment, but a moderate rise in white patients in this group.

The recurrences between 3 and 12 months are incomplete, as none of the patients who attended after July 1, 1957, have had a full year in which to become re-infected. The total is, however, complete up to June 30, 1958, and it seems very probable that a definite fall will be seen in this group also. 


\section{Discussion}

While there is no justification for trying to draw firm conclusions from a few cases in one area, the results do provide an interesting field for speculation.

(1) The figures show that the results of treatment in 1957 were not so good as in the previous year, but the rise in the failure rate in Birmingham occurred rather later than in some areas; possibly this was because of the sulphonamides given.

(2) The fall in recurrences during the first month between 1956 and 1957 is appreciably less than that during the next 2 months. This suggests that some cases of genuine relapse may have been classed as re-infections.

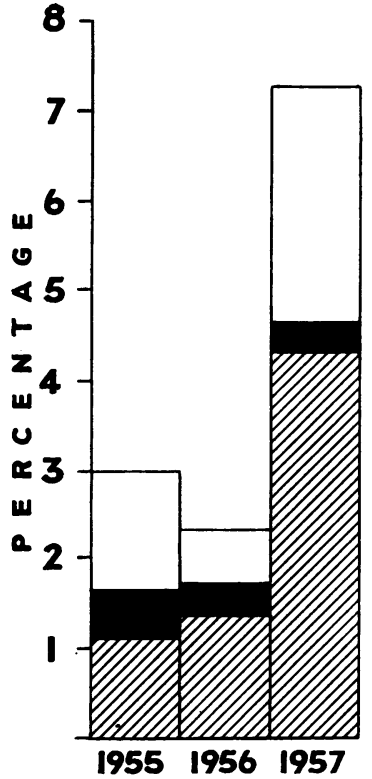

Fig. 3.-Failure rate.

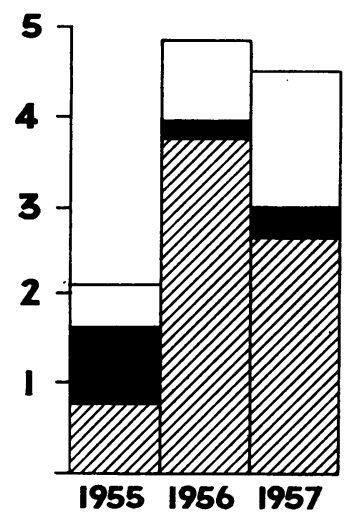

Fig. 4.-Recurrence in first month.

In the pre-penicillin era relapse in the first month was not considered impossible.

(3) The figures suggest that the tendency of the West Indians to become re-infected is diminishing. This may be because many are achieving a more stable home life or, possibly, because repeated infection is leading to some degree of resistance to the gonococcus.

(4) Despite the fall in recurrences, gonorrhoea is still increasing in Birmingham. The obvious cause is our inability to trace the carrier contacts.

TABLE VIII

FEMALE CASES OF GONORRHOEA

\begin{tabular}{c|ccccc|c|c|c}
\hline Year &. &.. &.. &.. &.. & 1955 & 1956 & 1957 \\
\hline \multirow{2}{*}{ Race } & White &. &. &.. & 83 & 124 & 187 \\
\cline { 2 - 7 } & West Indian & $\ldots$ &.. & - & 23 & 16 \\
\hline
\end{tabular}

WHITE MATIONALS

INDIANS, PAKISTANIS

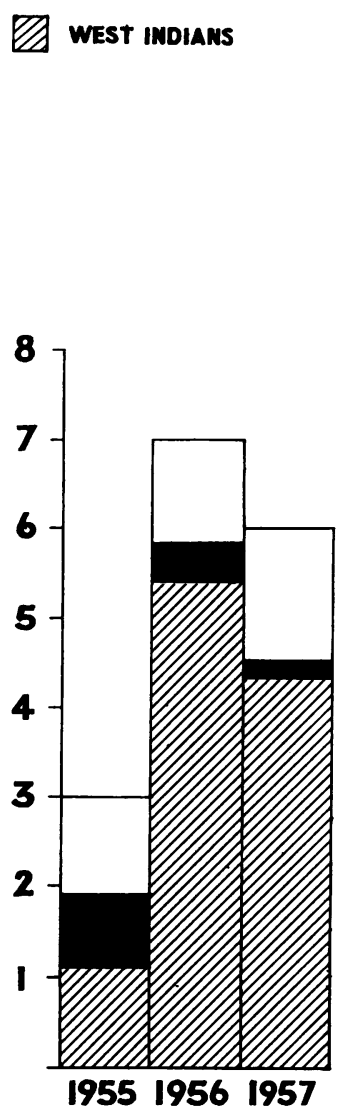

FIG. 5.-Recurrence in 1 to 3 months.

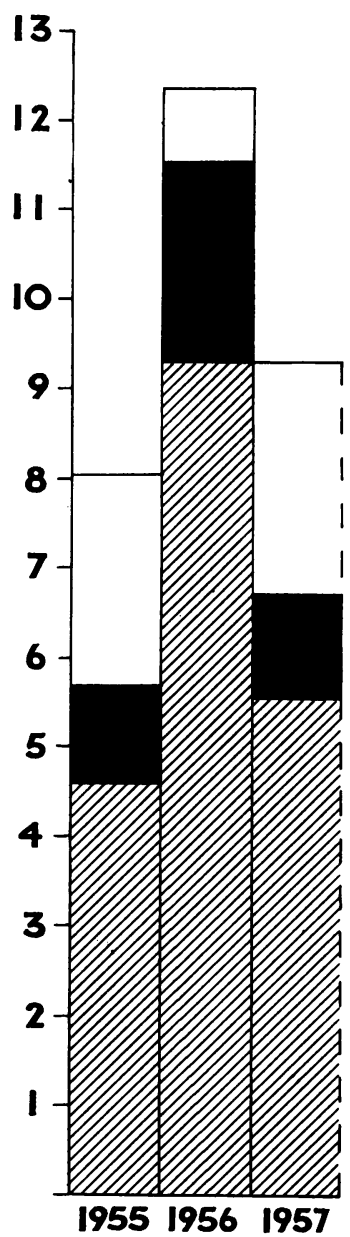

Fig. 6.-Recurrence in 3 to 12 months
The figures for female gonorrhoea are shown in Table VIII and Fig. 7.

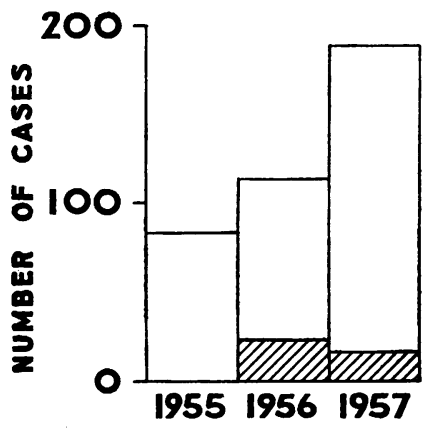

IFIG. 7.-Incidence of female gonorrhoea. 
In 1955 the number of West Indian women was very small and no separate record was kept. No Indian or Pakistani women have attended with gonorrhoea in the years under review. The Table shows that the majority of male infections must be acquired from white women. It is interesting to note that while we see many cases of latent syphilis in West Indian women the number attending with gonorhoea remains so small.

As evidence of the increasing danger of the gonorrhoea carrier, three cases of gonococcal ophthalmia have been seen in the last 2 months in babies whose mothers were unaware of their infection. There are other evident dangers in this increase in the incidence of gonorrhoea, especially when it is associated with a decrease in the efficacy of treat- ment. This year a generalized peritonitis of gonococcal origin and another case which was probably one of gonococcal septicaemia have been seen. In addition to these more dramatic cases, there is an increasing number of women with subacute gonococcal pelvic inflammation with its danger of subsequent infertility.

Finally, and this is dangerous ground, it may be asked if we are not curing gonorrhoea too quickly. Modern therapy encourages a mental outlook of "Easy go, easy come" and at the same time gives the patient little chance of developing any resistance to the infection. From an epidemiological point of view might it not be better if the patient had to suffer a little as in the old days? 